\title{
Rybalskyi Oleh,
}

Doctor of Technical Sciences,Full

Professor, Laureate of the State Prize of the USSR of Science and Technology, Professor at the National Academy of Internal Affairs, Kyiv, Ukraine,

ORCID ID 0000-0002-1440-8344

\section{Soloviov Viktor,}

Candidate of Technical Sciences, Docent, Deputy Head of the

Department, V.Dahl East Ukrainian

National University,

Severodonetsk, Ukraine

\section{Cherniavskyi Serhii,}

Doctor of Juridical Sciences, Professor,

Honored Worker of Science and

Technology, Pro-rector of the National

Academy of Internal Affairs,

Kyiv, Ukraine

ORCID ID 0000-0002-2711-3828

\section{Zhuravel Vadym,}

Candidate of Technical Sciences, Chief of the Laboratory, Kyiv Research and Expert and Criminalistics Center of the Ministry of Internal Affairs of Ukraine, Kyiv, Ukraine 


\section{FEATURES OF MODERN PROBABILISTIC TECHNOLOGIES OF JUDICIAL EXAMINATION}

The aspects of acceptance of probabilistic conclusion of expert, related to the construction of the crooked errors of the first and second family for an expert tool and being of measure of closeness between the identification signs got from different identifying objects, are examined in the article.

The necessity of acceptance of probabilistic conclusion is conditioned by that both a selection and measuring of parameters always will be produced by some error determined by exactness of work of the used instruments, that inherently to any technical device. In addition, identification signs abstracted from different identifying objects, absolutely identical parameters can not have. Therefore for comparisons of identification signs the probabilistic estimations of their closeness are used, i.e. the measure of closeness of two casual sizes or casual processes is estimated. Thus there always is some possibility of error, when from the existent error of measuring or error in exactness of estimation of closeness of parameters the signs produced by one object can be taken for what be going on from different sources, and signs what be going on from different objects, for what be going on from one source. Probability of origin of such errors is determined minimum exactness of the instrument intended for realization of concrete type of examination. Such errors name the errors of the first and second family.

Possibility of construction of modern tool is in-process shown on scientifically reasonable basis of the probabilistic going near a receipt and formulation of conclusions in the certificate of examination of difficult objects.

This approach leans against the obligatory construction of the crooked sizes of probability of errors of the first and second family. Their construction is conducted at development of expert tool on the basis of plenty of comparisons of pairs of standards, which provides authenticity of such curves. The use of such curves provides the receipt of complex estimation of value of minimum efficiency of expert tool at his development. These curves are used for realization of examinations for the receipt of probabilistic conclusion with the real sizes of errors of the first and second family. 
It is certain that during criminalistics authentication the error of the first family specifies on probability that the investigated objects are wrong identified as different, and error of the second family - on probability that different objects are wrong identified as one.

It is shown that the use of modern facilities of programming and treatment of information opens new additional possibilities at the construction of expert tool of difficult objects.

Keywords: expert opinion, probability, identification features, first and second type error curves, forensic identification, degree of proximity, forensic examination.

\section{REFERENCES}

1

$y$

, Soloviov V.I., Cherniavsky S.S., Zhuravel V.V., Zhelezniak V.K. (2019). Veroyatnostnyi

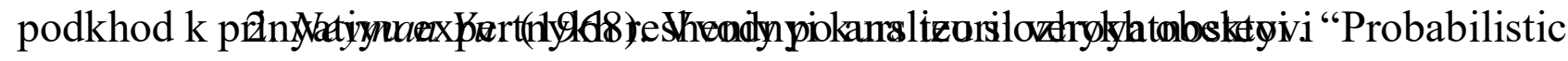

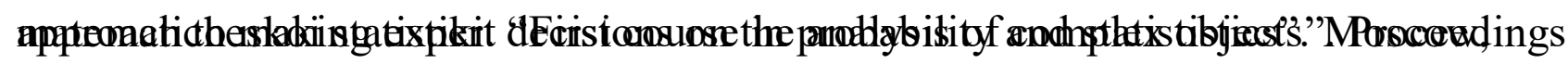

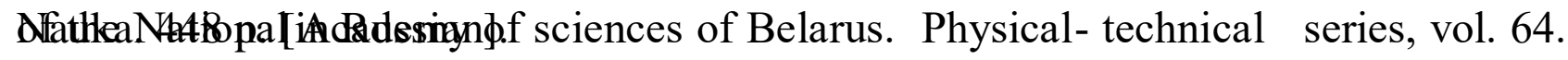

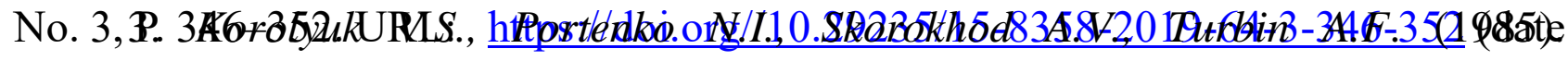

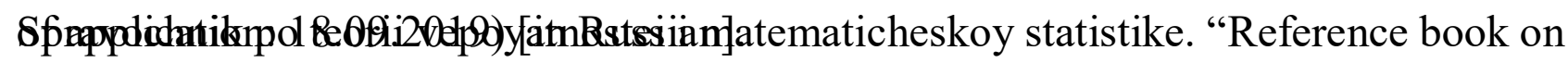
the theory of chances and mathematical statistics". Moscow, Nauka. 649 p. [in Russian]. 